\title{
On the Linguistic Consequences of Language Contact in Suriname: The Case of Convergence
}

\author{
Kofi Yakpo, Margot van den Berg and Robert Borges
}

\section{1 Introduction}

Suriname is often represented as a stratified mosaic of cultures and languages. The layers correspond to cultures and languages that entered Suriname via multiple migratory movements in different time depths. With languages from two major indigenous Amerindian families, several Afro-Caribbean English Lexifier Creoles and further dialectal varieties of Indo-European languages belonging to the Germanic cluster (English, Dutch) and the Italic cluster (French, Portuguese), Suriname already boasted an extraordinary linguistic diversity by the end of the eighteenth century. The Dutch labour trade of the last decades of the nineteenth and the first decades of the twentieth century added additional layers of complexity to the picture. After the abolishment of slavery in 1863, indentured labourers from North-Eastern India, Java, and Southern China brought their languages with them, adding representatives of major linguistic families of the world, namely Indic (Sarnami), Austronesian (Javanese) and Sino-Tibetan (Hakka or Keija). In the decades since the independence of Suriname in 1975, patterns of (circular) migration between the main city and plantations and villages along the coast and in the interior of Suriname, as well as between Suriname and the Netherlands have emerged. More recently, a new wave of Chinese immigrants has resulted in a sizable Cantonese and Mandarin speaking community. Furthermore, communities of Brazilians and Haitians are being formed, supported by the gold sector and through domestic/agricultural work, respectively. This mosaic of cultures and languages is often commemorated as an example of respect and tolerance; different ethnic and religious groups, each with their own unique cultural and linguistic characteristics, co-exist peacefully in a multicultural and multilingual society.

In this chapter, we challenge this somewhat static view of Suriname's cultural and linguistic diversity. The linguistic data that we present will show that languages in Suriname do not merely co-exist and that Suriname should not be characterised as a form of stable bilingualism and diglossia, where so-

(C) KOFI YAKPO ET AL., 2015 | DOI 10.1163/9789004280120_009

This is an open access chapter distributed under the terms of the Creative Commons Attribution-

Noncommercial 3.o Unported (CC-BY-NC,3.0) Likpense Margot van den Berg, and Robert Borges - 978900428012 
called minority groups maintain their languages for (informal) in-group communication and use the language of the dominant majority contact group for (formal) out-group communication. From the last quarter of the twentieth century onwards, changes can be observed in the distribution of languages across functional domains, as some of the languages are being used in more and other domains as before, resulting in what has been described in the literature as leaky or encroaching diglossia (Ferguson 1959; Dimmendaal 1989). In addition to changes in language use, changes in the linguistic systems of the languages are observed (Charry, Koefoed and Muysken 1983; Carlin and Arends 2002). Furthermore, a new code appears to be emerging; one that bears some resemblance to the mixed Sranantongo-Dutch language practices of people of Surinamese descent in the Netherlands (Breinburg 1983). We will focus on a particular outcome of linguistic change, that is the results of convergence. Due to convergence, (partial) similarities increase at the expense of differences between the languages in contact (Weinreich 1954: 395). In line with Matras and Sakel (2007) and others, we define convergence in more concrete terms as the adaptation of an element in language $A$ to match the scope and distribution of an element of language $B$ that is perceived to be its functional equivalent. We will show that Sranantongo has experienced a shift from primarily postpositions to prepositions in line with Dutch. Urban Ndyuka speakers are shifting their modal categories in the direction of Sranantongo. Sarnami is experiencing a shift to primarily svo word order in line with Sranantongo and Dutch.

Language change may result from language-internal processes such as grammaticalisation for example, or it may be contact-induced. As a contactinduced phenomenon, it is intimately connected to bi- or multilingualism. Thus it may not be surprising to find language change in Suriname. Carlin and Arends (2002: 1) observe that "hardly any inhabitant of Suriname is monolingual, yet not everyone is multilingual in the same languages, nor to the same extent". Indeed, $89 \%$ of the participants in a recent survey of the Nederlandse Taalunie claimed to speak more than one language regularly, $40 \%$ more than two (Taalpeilonderzoek 2011). However, multilingualism is not a sole prerequisite for language variation or language change. For example, the multilingual society of India is often cited to illustrate that multilingualism can be a strategy for minority language maintenance (Fasold 1993). However, this does not mean that the minority languages are not influenced by the languages with which they co-exist. Gumperz and Wilson (1971) study the longstanding multilingualism in the village of Kupwar, located in Maharashtra obliterated the differences between the languages in contact, resulting in a high degree of translatability between the Dravidian language Kannada and the Indic languages Kupwar Urdu and Marathi. In other villages, differences between these languages are 
not obliterated. The linguistic competence of many of the Kupwar residents are said to involve three distinct lexicons but a single grammar. As the distinct lexicons are maintained, social/ethnic identity can be marked via the use of different languages. Thus the languages are maintained.

The data collected by Kofi Yakpo, Robert Borges, and Stanley Hanenberg in Suriname in 2010 and 2011 suggests that the present language situation in Suriname differs from that of India, in that it is best characterised in terms of leaky or encroaching diglossia and language shift, rather than type of language maintenance found in Kupwar (cf. Yakpo and Muysken, in prep.). But instead of a shift to the language of the socially dominant group, as that type of shift occurs most frequently, the actual changes in the linguistic landscape of Suriname are more complex and differ across ethnolinguistic groups, functional domains and geographical locations. While Surinamese Dutch and Sranantongo are clearly expanding in terms of speaker numbers and language domains, their linguistic systems are also changing. Sranantongo as a person's second or third language differs in a number of ways from the variety of Sranantongo that is spoken as a first language (Migge and Van den Berg 2009). Furthermore, new codes appear to be emerging in which codeswitching and language mixing are so profound that the matrix language of the speaker may be difficult to determine, while other languages, such as Javanese and Mawayana, may be headed for extinction.

In the following sections, we will discuss the notion of convergence in some more detail. (section 2). We briefly address our data collection methods in section 3. In section 4, we discuss the language situation of Suriname in terms of language shift and language maintenance scenarios. Our linguistic data are presented in section 5 . Section 6 concludes the paper and spells out how the present language situation in Suriname can advance our thinking on multilingualism in relation to language change and language maintenance.

\section{On the Notion of Convergence}

In the previous section we described convergence as the adaptation of an element in language A to match the scope and distribution of a perceived functional counterpart in language B. But convergence has been described in various sub-disciplines of linguistics in a number of different ways. Kouwenberg (2001) compares the use of the notion of convergence in historical linguistics and creole studies, noting that it is used mostly as a descriptive concept in historical linguistics and in an explanatory manner in creole studies, "where it is interpreted as referring to multiple sources of creole forms or patterns and/or to multiple causation" (Kouwenberg 2001: 243). In studies on Second Language 
Acquisition, it is used to refer to the linguistic outcomes of a mostly psycholinguistic process in a bilingual or multilingual situation; the term convergence is applied to the new forms that result from putting elements together that were already present in existing language varieties. For example, "Quechua-Spanish bilingual children are observed to produce past tense forms that are associated with mirative features not manifest in non-contact Spanish, and in a Quechua condition, the children evince discourse-oriented background/foreground distinctions analogous to those marked by aspectual morphology in Spanish. These patterns emerge from convergence in the shared functional category of Tense, which is differentially specified for features of evidentiality in Quechua and for Aspect in Spanish" (Bullock and Toribio 2004: 92). It presupposes that speakers are at least bilingual and further, that they are able to exploit their knowledge and awareness of the properties of the grammars of the languages involved. Thus, convergence has been described as the "enhancement of inherent structural similarities found between two linguistic systems" (Bullock and Toribio 2004: 91), or as the "most parsimonious grammar that serves both languages” (Muysken 2000: 167).

In the field of contact linguistics, convergence refers to a multilingual situation in which languages change in ways that make them more similar. Here, convergence is the diachronic process that explains the emergence of new structures that do not have a single source but that were already present, albeit less prominently, in both languages. Furthermore, convergence may lead to new structures that may resemble both languages to some extent rather than a one language completely (Thomason 2001). Convergence is further used to explain situations that emerge when one language adopts structural features of another language or when the languages in contact adopt an identical compromise (Winford 2003). In this paper, we adopt a broader view of convergence as the operation of contact-induced changes that render some of the languages of Suriname more alike. Admittedly, this makes any instance of unidirectional borrowing a potential case of convergence. However, we continue to employ convergence for two reasons. One is the wish to differentiate the process (borrowing) from the medium or long-term result (convergence). The other is to point towards the complex nature of borrowing processes in Suriname that arises from the co-existence of two dominant languages, namely Dutch and Sranantongo, and their interaction as donor or source languages. Due to this circumstance, it is often difficult to attribute instances of contact-induced change in languages other than these two to a single source, and in some cases the changes may represent compromises between these two dominant languages. In this view, convergence is situated among other processes of language contact, in particular language attrition, language shift, language death and creole formation, that are sociolinguistically motivated. Convergence is 
particularly useful as a term to characterise what we see as the emergence of a linguistic area in Suriname, with its characteristically diffuse directionality and various types mutual structural accommodation of the languages involved.

Winford (2007) succeeds in bridging the above mentioned fields of contact linguistics and second language acquisition studies via an adaptation of Van Coetsem's work, in which two types of cross-linguistic influence, borrowing and imposition, agentivity and a bilingual speaker's linguistic dominance (proficiency) are cleverly combined to provide a unified framework of contactinduced language change:

The direction of transfer of linguistic features is always from the source language to the $\mathrm{RL}$, and the agent of transfer can be either the recipient language or the source language speaker. In the former case, we have borrowing (RL agentivity), in the latter, imposition (SL agentivity). Also highly relevant to the distinction between borrowing and imposition is the notion of language dominance. As Van Coetsem (2000: 84) explains, difference in linguistic dominance is the main criterion for distinguishing between recipient language and source language agentivity. In the former case, the recipient language is the dominant language of the speaker, while in the latter case, the source language is the dominant language. (Winford 2007: 27)

When this framework is applied to the various situations in which convergence has been observed, the following types can be observed:

TABLE 8.1 Types of convergence (adapted from Winford 2007)

\begin{tabular}{lllll}
\hline Type & Description & Agentivity & Mechanism & Languages \\
\hline Type A & $\begin{array}{l}\text { Most content morphemes } \\
\text { and some function items } \\
\text { are incorporated from a } \\
\text { source language into a } \\
\text { recipient language }\end{array}$ & $\begin{array}{l}\text { recipient language } \\
\text { agentivity }\end{array}$ & borrowing & $\begin{array}{l}\text { Media Lengua, } \\
\text { Ma'a }\end{array}$ \\
Type B & $\begin{array}{l}\text { Most content morphemes } \\
\text { come from one of the } \\
\text { languages, but there is a } \\
\text { more intricate mixing of } \\
\text { structural features from } \\
\text { both languages }\end{array}$ & $\begin{array}{l}\text { recipient + source } \\
\text { language agentivity imposition }\end{array}$ & $\begin{array}{l}\text { Aleut } \\
\text { bichif, Mednyj }\end{array}$ \\
\end{tabular}




\begin{tabular}{|c|c|c|c|c|}
\hline Type & Description & Agentivity & Mechanism & Languages \\
\hline Type $\mathrm{C}_{1}$ & $\begin{array}{l}\text { Outcomes in which } \\
\text { speakers of an ancestral } \\
\text { language have shifted or } \\
\text { are shifting to a socially } \\
\text { dominant language }\end{array}$ & $\begin{array}{l}\text { source language } \\
\text { agentivity }\end{array}$ & imposition & $\begin{array}{l}\text { Ganzhou } \\
\text { Chinese }\end{array}$ \\
\hline Type C2 & $\begin{array}{l}\text { Outcomes in which speakers } \\
\text { of an ancestral language } \\
\text { have shifted or are shifting to } \\
\text { a linguistically dominant } \\
\text { language, that is socially } \\
\text { subordinate }\end{array}$ & $\begin{array}{l}\text { source language } \\
\text { agentivity }\end{array}$ & imposition & Sranantongo \\
\hline Type $C_{3}$ & $\begin{array}{l}\text { Outcomes in which } \\
\text { speakers of an ancestral } \\
\text { language have shifted to a } \\
\text { socially and linguistically } \\
\text { dominant language, that } \\
\text { subsequently influences the } \\
\text { ancestral language }\end{array}$ & $\begin{array}{l}\text { source language } \\
\text { agentivity }\end{array}$ & imposition & $\begin{array}{l}\text { English- } \\
\text { influenced } \\
\text { Spanish in Los } \\
\text { Angeles }\end{array}$ \\
\hline
\end{tabular}

The question is then, what types of convergence can be encountered in Suriname? In the following sections we will report on contact-induced change in three languages of Suriname, namely Sranantongo, Ndyuka and Sarnami in three language contact constellations that are typical for Suriname: contact with Dutch as the agent and another language (in this case Sranantongo) as the undergoer of a linguistic change (section 5.1), (section 5.2 ) contact between Sranantongo, Dutch and a third language (in this case Sarnami), and lastly contact with Sranantongo as the agent and another language (in this case Ndyuka) as the undergoer of change (section 5.3).

\section{3}

\section{Methods and Data}

The linguistic data on which this article relies was gathered in Suriname in 2010-11 as part of the E RC project "Traces of Contact" at the Centre for Language Studies at Radboud University Nijmegen. The corpus contains recordings of the following eight languages of Suriname: Four English Lexifier Creole languages, namely Sranantongo, Ndyuka, Kwinti and Saamaka, three languages of Asian 
origin Sarnami, Javanese, Hakka and finally Surinamese Dutch. Comparative data has been collected in India, the Netherlands, West Africa and Mauritius. The corpus consists of a total of about a hundred and fifty hours of data. All language examples in this paper that come without a bibliographical reference stem from our own field data.

The recordings include elicited speech gathered through the use of visual stimuli such as pictures, picture books and video clips, as well as more naturalistic discourse ranging from semi-structured interviews to unguided conversations. Additionally, some fifty sociolinguistic interviews were conducted on Sranantongo on the backgrounds of speakers and their attitudes vis-à-vis the languages they speak. Our corpus is well balanced in that it represents speech from various parts of the coastal area and the interior, from members of the different linguistic communities, and from an age range of fifteen to ninety years.

4

\section{Socio-historical and Linguistic Aspects of Multilingualism in} Suriname

This section addresses the socio-historical context of multilingualism in Suriname. We discuss key historical events leading to the rise of linguistic diversity in the country, as well as the face of multilingualism in contemporary Surinamese society. We look at language maintenance and language shift, and aspects of language use, demography and the relative status of the languages of Suriname. The combination of these socio-historical factors renders a scenario that is particular to Suriname, in which linguistic diversity and societal multilingualism coincide with language use patterns favouring the two "big" languages Sranantongo and Dutch. We hypothesise that this scenario in turn produces the kind of linguistic convergence that we go on to describe in section 5 .

Since the 1980s, most studies on language contact in multilingual societies follow a scenario-based approach. Languages are not entities that exist on their own accord; "... the history of a language is a function of the history of its speakers, and not an independent phenomenon that can be thoroughly studied without reference to the social context in which it is embedded" (Thomason and Kaufman 1988: 4). Two scenarios are generally distinguished, that is a scenario of language maintenance or stable diglossia, and a scenario of language shift. The former refers to a scenario in which linguistic minorities maintain their languages alongside the language of the majority, while the linguistic minorities shift to the language of the majority in the latter scenario. The shift may be caused by several factors, that include the expected positive change in the socio-economic status when an ethnolinguistic minority group 
shifts to the language of the majority group and further, the diminishing status of a minority language, the demographic strength of the minority and its geographic distribution, whether or not the language receives institutional support, if it used in mass media and/or education (Appel and Muysken 1987). In the following sections, we will discuss how these factors contribute to the language situation in Suriname, but first we will give a brief overview of some important historical time periods in which population movements and recompositions had such profound demographic, cultural, social, economic, political, and linguistic consequences that they dramatically changed Suriname's linguistic landscape.

\section{Early Colonial Period (1500-1850)}

(1) After the arrival of the first European explorers and traders on the Caribbean coast of the Guianas (including the territory we now know as Suriname) in the early sixteenth century, contact with the European invaders led to the dramatic decline of the indigenous American population of the area through the genocidal combination of imported disease, warfare, and enslavement (see Carlin 2002). We can assume that the degree of depopulation of Suriname paralleled that recorded for other parts of the Guianas and North-Eastern Brazil, where an estimated $95 \%$ of the indigenous population perished in the first 50 years after contact and conquest (see Wright 1999: 364). The linguistic consequences of depopulation, population movements, and subsequent contacts with the coastal populations and later Maroons have been a long-drawn process of language shift and death of the indigenous languages in Suriname (cf. Carlin 2002).

(2) The total number of enslaved Africans brought to Suriname between 1651 and 1826 has been estimated between 215.000 and 250.000 (Oostindie 1993; Voyages Database 2009), resulting in deeply transformative demographic changes on both sides of the Atlantic. In addition to the Trans-Atlantic trade, enslaved Africans and their descendants entered Suriname via trade with other Caribbean colonies including the Dutch Antilles, the French West Indies, as well as English and Danish colonies (Van Welie 2008).

(3) As long as enslaved Africans were brought to Suriname, individuals and small groups chose to flee the plantations and form free Maroon societies in the interior (see Price 1983; Dragtenstein 2002; Thoden van Velzen and Hoogbergen 2011). Although these movements were not very substantial in numerical terms, they were decisive for a recomposition of Surinamese society along coastinterior axis in terms of geographical, economic, socio-cultural and linguistic characteristics. The geographical detachment of the Maroons from the coastal belt led to linguistic divergence of the maroon creole languages from the 
common coastal creole varieties referred to in the literature as "ProtoSranantongo" or "Early Sranan" (cf. Van den Berg 2007), and the formation of a western and eastern cluster of maroon creole languages.

\section{Late Colonial Period (1850-1970)}

(4) Economic transformations in the Atlantic world and the struggle against slavery by the African-descended population of the Americas and European abolitionists led to the gradual erosion and eventual abolition of the institution of slavery in the nineteenth century. Before slavery was abolished in Suriname in 1863 , the Dutch colonial government sought to ensure the availability of cheap labour for the plantation economy by importing Asian indentured labourers. About 2000 migrants arrived from Java and Southern China between 1853 and 1875 (see Tjon Sie Fat, this volume). Following that, agreements were brokered with the British for the provision of cheap labour from India in 1870 (Hoefte 1987). Through these arrangements, 34,304 (male and female) labourers were shipped to Suriname from India between 1873 and 1916 (Marhé 1985: 7). The linguistic result was the koineisation of several closely related languages spoken in the present-day Indian federal states of Uttar Pradesh, Bihar, and Jharkhand (Damsteegt 1988).

(5) A second response was the transfer of workers from the Dutch colony of Oost-Indië, i.e. Indonesia, with 32,956 Javanese arriving in Suriname between 1890 and 1940 (Hoefte 1987: 3). The Chinese indentured labourers were by now being complemented by chain migrants from Southern China; this pattern continued up to the present (Tjon Sie Fat 2009a: 66-68). The linguistic results are the establishment of Javanese in Suriname, as well as the Southern Chinese languages Hakka and Cantonese.

\section{Postcolonial Period (1970-Present)}

(6) In the years leading up to full independence in 1975, there was a mass emigration of Surinamese citizens. Some forty thousand Surinamese, mostly AfroSurinamese and Indo-Surinamese from the Paramaribo district, migrated to the Netherlands in 1975 (Choenni and Harmsen 2007). In 2010, some 345'000 individuals were classified as "Surinamese" in the Netherlands by the Dutch Central Bureau of Statistics (2011). One consequence of this demographic development has been the establishment of patterns of circular migration between the Netherlands and Suriname for motives as diverse as business and work, family and leisure, and arts and culture. This process has given rise to a transnational social space, in which goods, people, ideas, and language practices are continuously exchanged across the Atlantic, and further, to transnational communities (cf. Gowricharn 2009; Oostindie and Schoorl 2011). A 
second consequence has been the establishment of Sranantongo as an important and highly visible heritage language in the Netherlands and its acquisition of local characteristics. A third consequence is the decline of other Surinamese languages in the Netherlands through language shift to Dutch, and to a lesser degree, Sranantongo (as well as a leveled Maroon language in certain settings). In particular, Sranantongo may be developing into a supra-ethnic identity code for Dutch people of mostly Afro-Surinamese descent in the Netherlands, even though the second Dutch-born generation more often than not has little proficiency in the language. The vitality of Sranantongo in the Netherlands seems to be mainly subscribed to the Surinamese-born and the first generation of Dutch-born Creoles, as they are numerically dominant (Choenni and Harmsen 2007). Furthermore, cultural organisations contribute to the vitality of Sranantongo in the Netherlands. The society Ons Suriname, for example, organises the annual Sranantongo dictee, a spelling competition intended to promote the correct use of Sranantongo. In addition, transmigration may have a positive influence on the vitality of Sranantongo in the Netherlands as transmigrants may be influenced by the language practices that they encounter in Suriname. On a different note, Sranantongo is an important lexical source for youth language in the Netherlands (Hardenberg 2003).

(7) A second migratory movement out of Suriname was triggered by the civil war, which ravaged large parts of the interior between 1986 and 1992 (see Vries 2005). Violence and economic deprivation led to refugee movements to the Netherlands and the United States, among other places, but mostly across the border into French Guiana. At least 10.000 Surinamese left the country for its eastern neighbour. This led to the firm establishment of the Maroon Creoles Saamaka and Ndyuka/Pamaka in French Guiana (Migge and Léglise 2013). Furthermore, heightened cross-border mobility (ibid.), the economic take-off in the interior after the war and circular migration between the interior and the coast (van Stipriaan 2011, this volume) are factors that have also been leading to increased contact between the various Maroon Creoles and Sranantongo, and convergence between these languages (Migge and Léglise 2013: chaps. 7-9).

(8) Suriname's increasing integration into regional and global economic networks has also been reflected in the emergence of new migratory currents into Suriname; next to an older pattern of migration from neighbouring Guyana, newer currents include substantial labour migration from Brazil, particularly into the artisanal mining sector in the interior (de Theije, this volume), Haitian (non-) transitory migration since the beginning of the twenty-first century (Laëthier, this volume), reinvigorated migration from increasingly varied locations in China (Tjon Sie Fat, this volume) and last but not least a not insignificant reimmigration of Dutch citizens of Surinamese extraction and 
Europeans of non-Surinamese origin from the Netherlands and elsewhere. These new immigrant languages are now participating in the multilingual dynamics of present-day Suriname and have further added to the diversity of the language situation. These newcomers also learn Dutch and particularly Sranantongo. Thus these languages are growing in terms of speaker numbers on the one hand. On the other hand, variability increases and new language practices emerge that are associated with the newcomers.

(9) The dynamics of the processes described above, in particular those in post-colonial times, may be summarised as an increase in physical mobility of people and goods, an increase in communicative density, an increase in outward orientation and many of the other factors that have been described for other societies of the South under the heading of "globalisation". This constellation has given Sranantongo and Dutch a decisive edge in the processes of the linguistic scenario described above.

The linguistic consequences of the developments outlined above are summarised in Table 8.2 (the numbers in Table 8.2 refer to the numbers in the preceding three paragraphs):

TABLE 8.2 Migratory processes and linguistic consequences

No. Description Linguistic outcome Languages concerned

(1) Decline of indigenous

languages

2) Creation of a coastal creole language

(3)

Differentiation of Maroon creole languages

(4)-(5) Arrival of Asian indenture languages

(4)

Creation of Indian koine

Sarnami

(6) Strong influence of Dutch on

Sranantongo in Netherlands

Decline of Surinamese languages in Netherlands

(7) Koineisation of Maroon languages
Within 3 decades: Akuriyo,

Tunayana, Sikïiyana,

Mawayana (Carlin 2002: 43)

Language creation Proto-Sranantongo

Saamaka, Matawai Ndyuka, Paamaka, Aluku, Kwinti

Diversification

Sarnami, Javanese, Hakka,

Cantonese

Bhojpuri, Awadhi, Magahi,

Maithili

Divergence Sranantongo

Language shift

Affects all languages of

Suriname

Convergence

Western and Eastern

Maroon Creoles 
No. Description

Arrival of new immigrant

languages

(9)
Sranantongo and Dutch acquire an ever-growing number of $\mathrm{L} 1$ and $\mathrm{L} 2$ speakers

Linguistic outcome Languages concerned

Diversification

Creolese, Brazilian

Portuguese, Cantonese, Mandarin, Haitian

Convergence, language shift
Affects all languages of

Suriname

\subsection{On Language Use and Language Attitudes in Suriname}

Recent census data and surveys present interesting perspectives on language use in Suriname. The 2004 census of the General Bureau of Statistics Census Office of Suriname is the only census so far to list Surinamese households of all districts by language use. Households were asked to name the "language spoken most often" and the "second language spoken". The resulting figures are reproduced in 8.3:

TABLE 8.3 Languages spoken in households

\begin{tabular}{|lccrrr}
\hline Language & \multicolumn{3}{l}{$\begin{array}{l}\text { Language spoken most often } \\
\text { Speakers }\end{array}$} & In \% & \multicolumn{2}{l}{$\begin{array}{l}\text { Second language spoken } \\
\text { Speakers }\end{array}$} & In \% & Total \% \\
\hline Dutch & 57.577 & 46,6 & 29.163 & 23,6 & 70,2 \\
\hline Sranantongo & 11.105 & 9,0 & 45.634 & 37,0 & 46,0 \\
\hline Sarnami & 19.513 & 15,8 & 8.121 & 6,6 & 22,4 \\
\hline Javanese & 6.895 & 5,6 & 6.846 & 5,5 & 11,1 \\
\hline Maroon languages* & 18.797 & 15,2 & 2.493 & 2,0 & 17,2 \\
\hline Others & 6.501 & 5,3 & 4.030 & 3,3 & 8,6 \\
\hline No 2nd language** & $\mathrm{NA}$ & - & 23.754 & 19,2 & 19,2 \\
\hline Unknown & 3.075 & 2,5 & 3.422 & 2,8 & 5,3 \\
\hline Total & 123.463 & 100 & 123.463 & 100 & 200 \\
\hline
\end{tabular}

(Source: SIC 213-2005/02. Zevende algemene volks- en woningtelling in Suriname, landelijke resultaten, volume I, demografische en sociale karakteristieken (7th general population and household census in Suriname, national results, volume 1, demographic and social characteristics). Paramaribo: Algemeen Bureau voor de Statistiek)

* Named: Saramaccan, Aucan, Paramaccan in the census, ${ }^{* *} \mathrm{NA}=$ Not applicable 
Table 8.3 displays a clear bias towards Sranantongo and Dutch. These two languages are the only ones that manifest significant differences between "most often" and "second language" uses. Sranantongo and Dutch are the only languages to function as lingua francas, i.e. out-group mediums of communication, in a significant way in addition to their use as community languages. But how do the surprisingly high figures of 47 per cent for Dutch as a "most spoken" language come up? Why do speakers appear to have no allegiance to Sranantongo as a "first" language ( $9 \%)$ and almost exclusively name it as a second language $(37 \%)$ ?

First of all, it appears that Dutch, in particular Surinamese Dutch, has indeed been making further inroads into Surinamese society. Dutch is the dominant language of instruction in school, and the extended reach of Dutchbased audio-visual media and the formation of a transatlantic Surinamese area after independence due to emigration, remigration, and transmigration have contributed to this development. Sranantongo is also expanding, but this fact is only reflected in the correspondingly high second language allegiance. A large proportion of Surinamese actually speaks Sranantongo as a second or third language on a daily basis, but will not admit to this when asked. When Surinamese are asked about the languages they use, they name the languages they prefer. The figures in Table 8.3 suggest that the discrepancy between actual patterns of use and language attitudes appears to be the most accentuated with respect to Dutch and Sranantongo. We attribute the low percentage of Sranantongo as "language spoken most often" to the differences in prestige that Dutch and Sranantongo enjoy, which leads to an overrepresentation in the case of Dutch and under representation in the case of Sranantongo.

Two recent surveys confirm these suspicions. Kroon and Yagmur (2010) list the following top fourteen home languages in a large sample of primary and secondary school students across Suriname in a 2010 study supported by the Nederlandse Taalunie (the Dutch language standardising agency of which Suriname, the Netherlands and Belgium are members). Table 8.4 conflates first and second (or third, or fourth) language uses by giving total percentages. The language names in Table 8.4 are the ones used in the source:

TABLE 8.4 Figures from the Taalunie micro-census on home languages (Kroon and Yagmur 2010: 186 )

\begin{tabular}{|c|c|c|}
\hline Language & Spoken as home language & In \% \\
\hline Dutch & 20.137 & 88,9 \\
\hline Sranantongo & 13.761 & $6 o, 7$ \\
\hline Sarnami & 6.853 & 30,3 \\
\hline
\end{tabular}




\begin{tabular}{lcc}
\hline Language & Spoken as home language & In \% \\
\hline English & 4.606 & 20,3 \\
Javanese & 3.497 & 15,4 \\
Ndyuka & 2.561 & 11,3 \\
Saamaka & 2.200 & 9,7 \\
Spanish & 359 & 1,6 \\
Portuguese & 325 & 1,4 \\
Chinese & 313 & 1,4 \\
Paamaka & 250 & 1,1 \\
Arawak & 212 & 0,9 \\
Aluku & 162 & 0,7 \\
Carib & 160 & 0,7 \\
\hline
\end{tabular}

In the Taalunie survey, Dutch figures once more as the top runner of all home languages. In the three districts of the interior put together, the score for Dutch as (one of the) home languages is much lower, but with $27 \%$ (Kroon and Yagmur 2010: 43) still scores higher than expected. In fact, such high scores for Dutch as a home language in the interior do not tally with the admittedly impressionistic observations made by us and other linguists who have worked on the languages of Suriname (e.g. Renata de Bies, p.c.; Hein Eersel, p.c.; Bettina Migge, p.c.). They therefore seem unlikely indicators of actual language use in the three districts of the interior. Another hint towards the attitudinal nature of these figures is the surprisingly high score for English. Even abstracting from a strong presence of Creolese (the English-lexicon creole of Guyana) in Guyanese immigrant families in Suriname, a figure of 20 per cent seems excessively high. The figure for English is therefore more likely to reflect the high and growing prestige of English in Suriname rather than actual practice in Surinamese homes.

Contrary to Kroon and Yagmur 2010, Léglise and Migge (this volume) explicitly point to the attitudinal nature of the figures rendered by their recent survey conducted amongst school children. Here too, we find the usual combination of unexpectedly high scores for Dutch, surprisingly low, but still significantly high scores for Sranantongo and more balanced scores for all other languages.

Of course such subjective speaker assessments in themselves have a highly objective information value. They tell us something about language attitudes, as mentioned above. But we suspect that the high scores for Dutch also tell us something about the perceived presence of Dutch in multilingual interactions in households. This presence may range from the use of single Dutch 
lexical items, through light to heavy code-switching with Dutch, to a largely monolingual use of Dutch. The same holds for Sranantongo even if its perceived presence in household interactions is lower. The national census data, the Taalunie and the Léglise and Migge survey (this volume) therefore give us valuable insights into the nature of multilingualism in Suriname, even if their use for determining actual language practices is limited by their very nature.

The situation with respect to the other languages listed in Table 8.3 and Table 8.4 is similar. For example, Sarnami is seen as an in-group language par excellence. This is confirmed by official census data from 2008 from the districts of Paramaribo and Wanica, that aligns ethnic and language background (cf. SIC 261/2009-08). The data show a minute percentage of members of other self-classified ethnicities claiming Sarnami as a "mother tongue", namely o,5 percent for people who claim Javanese ethnicity and a gaping $0 \%$ for those who self-identify as "Kreool" (Afro-Surinamese except Maroon).

However, the data on "mother tongue" background alone could allow the conclusion that Sranantongo is also chiefly an in-group language. It also gets exceedingly low scores as a mother tongue, namely $1 \%$ and $2 \%$ respectively for those who self-identify as "Hindostaan" (Indo-Surinamese) and Surinamese Javanese respectively. Even more surprisingly, Sranantongo even gets a low score of $13 \%$ as a mother tongue within the Afro-Surinamese group-with more than $80 \%$ claiming Dutch as a "mother tongue". The situation is similar, though not as striking, with those who identify as "Hindostaan" (IndoSurinamese) — here $24 \%$ claim Dutch as a "mother tongue". Although a strong allegiance with Dutch and a symbolic rejection of Sranantongo as a primary language may be typical of these two (peri-)urban districts, our own research in the district of Saramacca for example, revealed older patterns of multilingualism beyond the Sranantongo-Dutch axis. Quite a few people with whom we conducted extended sociolinguistic interviews claimed that their parents or grandparents above fifty years of age had a good command of Sarnami and Javanese although they did not self-identity as the corresponding ethnicity. Beyond that, and quite to the contrary of what may be deduced from the national census and survey data presented so far, our sociolinguistic interviews in all districts of Suriname except Sipaliwini and Marowijne revealed very positive attitudes towards Sranantongo, when the language of interaction between interviewer and interviewee in sociolinguistic interviews was Sranantongo rather than Dutch.

Even if such qualitative data may not easily be compared to quantitative data, our observations point to the complexity of the relationship between language attitudes and actual practices. The analyses of the census and survey 
data, as well as our own observations show that use patterns are only partially coterminous with ethnic identification.

\subsection{On the Impact of Demographic Strength of Ethnolinguistic Groups and Their Geographic Distribution on Language Use}

While it is often true that the demographic weight of an ethnolinguistic minority group in a geographical location in relation to the majority group determines the degree of language use and maintenance within the minority community (Fasold 1993), it is not the case for Suriname. Until the 1970s, Afro-Surinamese were the numerically dominant group in Suriname and the historical standardsetting role of the Afro-Surinamese population with respect to both Surinamese Dutch and Sranantongo is referred to by Blanker and Dubbeldam (2005) and de Bies et al. (2009) among others. In the years before and after independence, the Indo-Surinamese population became the numerically dominant group. The population census of 1972 lists $142.917(37,6 \%)$ as "Hindostaans" (IndoSurinamese) and $119.009(31,4 \%)$ as "Kreool" (Afro-Surinamese). The census of 2004 lists $135.117(27,4 \%)$ as "Hindostaans" and 87.202 as "Kreool" (17,7\%) (Algemeen Bureau voor de Statistiek, Paramaribo 2005). Despite the relative numerical decline of those self-identifying as "Kreool", the language that is originally associated with this group is expanding, see the previous section. There are more speakers of Sranantongo in Suriname than there are people who self-identify as "Kreool". At the same time, Sarnami, the language of the numerically dominant group of Indo-Surinamese, seems to be losing ground. Thus, Suriname shows that the size of an ethnolinguistic group is not an exclusive indicator of language use and maintenance.

Given the absence of any systematic geo-linguistic survey of the languages of Suriname, it is equally difficult to assess the degree of geographically determined variation. The only language for which we have conclusive evidence for the existence of a geographically defined variational space is Sarnami-Marhé (1985) lists a number of lexical and grammatical features that differentiates between a western, Nickerie-based variety and the variety spoken further east along the coast. In our corpus, many speakers however mix features from the two ends of the supposed variational space. For example, the same text produced by the same speaker may contain the past tense morpheme /-is/ as in $u$ á-is 's/he came', next to the functionally equivalent /-il/ as in $u$ á-il. Marhé (ibid.) classifies the latter morpheme as typical for Nickerie Sarnami, while the former is seen as an exponent of the eastern variety. This points to the difficulty of determining discrete linguistic boundaries in a society such as Suriname, with a small, increasingly mobile population, characterised by dense and 
multiplex social networks. This is equally relevant for the possibility of an urban-rural divide, for example as posited by us in the following section with respect to Ndyuka. Although we use this opposition as an analytical frame, we contend that the urban-rural linguistic boundary has become brittle, and is better seen as a multivariate space in which language, linguistic practice, locality — both geographically and in terms of speaker perception — and mobilityboth socio-geographically and in terms of communication technology (e.g. mobile phones, see Van Stipriaan, this volume) interact in various ways (see Pennycook 2010; Lawrance 2007).

\subsection{Institutional Support and Education}

Few countries have followed the example set by South Africa, which established the possibility to use one's native language in institutional settings as a fundamental human right for all citizens in its constitution of 1996. In Suriname, the debate on language policy is highly politicised which has made government support for any language other than Dutch a difficult matter (Gobardhan-Rambocus 1989, 2006). In March 2011, a steering committee was formed to prepare the ground for the foundation of a language council. At present, however, there is little government support for any of the Surinamese languages and multilingualism is not officially supported. On the other hand, foreign financed agencies have been active in Suriname. The Nederlandse Taalunie (Dutch language union), the Dutch language standardising agency, is present in Suriname. Although the Nederlandse Taalunie does not exercise the type of cultural diplomacy known from larger agencies such as the Alliance Française, the British Council or the German Goethe Institute, the Nederlandse Taalunie does have a considerable degree of soft power in its capacity to influence perceptions about the present and potential roles of Dutch in Surinamese society through personal and institutionalised networks with Surinamese intellectuals and academics and its capacity to finance and disseminate studies such as Kroon and Yagmur (2010). This is all the more the case given that there is no department of modern languages or linguistics at the Anton de Kom University, the national university of Suriname, that could galvanise and organise local expertise on language issues. Likewise, The Summer Institute of Linguistics was present from 1968 to 2001 and through its dictionary and bible translation projects, has made an important contribution to the standardisation and normalisation of Surinamese languages like Sranantongo, Sarnami, Ndyuka, and Saramaccan.

The socio-demographic turn after World War II led to increased access to education, economic advancement and participation in the political sphere by other ethnic communities than the old Afro-Surinamese elite, particularly 
the big three communities of Indo-Surinamese, Javanese and more recently, Maroons. One possible consequence of a growing assertiveness of the other communities is that formerly marginal(ised) speech features in both Dutch and Sranantongo, considered to be characteristic of non-core, hence non-AfroSurinamese practices might be moving to centre-stage and losing whatever stigma they might have had. In fact, we might have to consider the possibility that adstrate and substrate effects in the Sranantongo speech of the non-AfroSurinamese majority may be encroaching upon the Sranantongo variety spoken by the Afro-Surinamese community itself.

Nevertheless, we would like to point out that so far, the presence of AfroSurinamese language practices and features is highly visible in the Sranantongo and Dutch spoken by all ethno-linguistic groups of Suriname. Even a cursory glance at de Bies et al's Dictionary of Surinamese Dutch (2009) shows the preponderance of Sranantongo loans and calques. This "standard-setting" role, so far, is probably due to a "founder effect" (see Mufwene 1996), in which for the longest time, Afro-Surinamese language practices have dominated the linguistic space of Suriname, and which successive waves of "late-comers" have adapted to.

The dimensions and the flexibility of language use patterns are perhaps best captured in the words of one of our participants, a 53 year old working-class male, who self-identifies as "Hindostaan" (Indo-Surinamese):

Luku doorgaans te mi de na wroko, nanga mi chefyere, mie taki Nederlands, af en toe Neger-Engels. Ma te mi de nanga mi collega, werk-collega dyaso, mi e taki Nengre. Yu abi wantu Hindustani, dan mi e taki Hindoestaans nanga en. ${ }^{1}$

A consequence of the entrenchment of Sranantongo and Dutch in far more domains than other languages of Suriname, as well their usefulness as languages of wider communication, as well as their overt and covert prestige, is that these two languages function as "attractors". They exert influence on the other languages in a non-reciprocal or unbalanced way. Sranantongo and Dutch provide lexical items and grammatical structures to the other languages of Suriname and to each other, and by this process act as agents of change and targets of convergence and language shift.

1 'Look, usually, when I'm at work, with my boss, right, I speak Dutch, sometimes Sranantongo. But when I'm with my colleagues, I speak Sranantongo. When there are a few IndoSurinamese, then I speak Sarnami with them." 


\subsection{Mass Media}

Language use in the public domain via mass media can have varying degrees of influence on language shift and language maintenance. While the impact of language use on radio and television on language maintenance in Suriname has not yet been systematically researched in detail, it appears that most ethnolinguistic groups are represented by at least one radio/tv station. Paramaribo has some 30 radio stations and 15 television stations, Nickerie has 12 radio stations and 4 television stations. Four radio stations are located on the banks of the Boven-Suriname river and the Tapanahoni river and even Galibi has a radiostation (Ramnath 2012).

While in the 1970s and 1980s, literary activity in particularly Sranantongo was booming via prose, poetry and plays, it is less booming nowadays. Schrijversgroep ' 77 is still active though, hosting monthly events in Tori Oso and distributes prose and poetry in various languages via their website (http://www.schrijversgroep77.org/). On the other hand, Suriname has a vibrant musical scene in which rappers and spoken word artists use Dutch, Sranantongo, Ndyuka and other languages of Suriname. Furthermore, messages on various discussion boards on websites such as Waterkant, Anda Suriname, Suriname.nl and Culturu.com among others, show that even though Dutch is the only language of instruction in the schools of Suriname, this does not prevent the people of Suriname from writing in languages other than Dutch.

TABLE 8.5 Language use on a selection of radio stations in Suriname

\begin{tabular}{llll}
\hline Station name & Region & Language choice & \\
\hline SRS & Public national station & Nation-wide & $\begin{array}{l}\text { Dutch, Sranantongo } \\
\text { Apintie }\end{array}$ \\
Private & Nation-wide & $\begin{array}{l}\text { Dutch, Sranantongo, } \\
\text { Sarnami }\end{array}$ \\
RP The Hot One & $\begin{array}{l}\text { Rapar Broadcasting } \\
\text { RP Noer }\end{array}$ & Paramaribo, Nickerie & Dutch, Sranantongo \\
& $\begin{array}{l}\text { Rapar Broadcasting } \\
\text { RP ACME }\end{array}$ & $\begin{array}{l}\text { Paramaribo, Nickerie } \\
\text { Rapar Broadcasting }\end{array}$ & Sarnami, Dutch \\
Radio Ishara & $\begin{array}{l}\text { Rapar Broadcasting } \\
\text { Network }\end{array}$ & Nickerie & Sarnami \\
\hline
\end{tabular}

Source: Ramnath 2012 
Many of these messages are mixed, they include Dutch and Sranantongo, Saramaccan, Sarnami, Ndyuka, etc.

\section{Convergence in Suriname: Linguistic Data}

In the previous sections, we discussed various historical and social factors that have contributed to shaping the linguistic landscape of Suriname. The preceding discussion revealed a scenario characterised by a complex layering of historical and contemporary social, political and economic processes that have placed the languages of Suriname into particular relationships to each other. In the current section, we will present some linguistic data that may be taken to reflect the workings of the social forces outlined in section 4. The languages covered in the following are Sranantongo, Sarnami and Ndyuka. In the following, we focus on two domains, namely constituent order of locative phrases and basic clauses, as well as the expression of tense, mood and aspect. The data presented in this section seems to indicate that these languages have been undergoing quite substantial change in recent times. We hypothesise that these changes are contact-induced and reflect the influence of the two most widely spoken languages of Suriname, namely Sranantongo and Dutch. At the moment, these changes seem to occur within a context of language maintenance. We do not, however, discard the possibility that some of these changes may be reflective of an ongoing language shift. This may be the case for Sarnami, for example.

\subsection{Locative Constructions in Sranantongo}

In this section, we cover contact-induced change in phrasal constituent order in Sranantongo. We conclude that contact with Dutch has led to the consolidation of locative constructions in contemporary Sranantongo, which resemble their Dutch counterparts more than those found in earlier varieties of Sranantongo.

Sranantongo and the other creoles of Suriname have long been noted for their use of postpositions in the expression of spatial relations (see, e.g. Muysken 1987). In the following sentence, the Sranantongo locative element ondro 'under(part)' co-occurs with an additional locative element, the general locative preposition na 'LOC'. Unlike its English and Dutch counterparts 'under' and onder, Sranantongo ondro also appears in a post- rather than a prenominal position. Postpositional locative constructions in Sranantongo (and in the Maroon creoles) have been convincingly argued to have arisen due to 
the influence of patterns found in the Gbe substrate languages of the creoles of Suriname (Bruyn 1996; Essegbey 2005):

\begin{tabular}{|c|c|c|c|c|}
\hline$a$ & buku de & $n a$ & $a$ & tafra \\
\hline DEF.SG & book be.at & LOC & DEF.SG & table \\
\hline
\end{tabular}

Postpositional locative elements already occur in historical records in such complex locative structures, as found in (2):

(2) sinsi a komm na hosso inni.
since 35Gcome LOC house inside
'since she entered the house.' (Sranantongo; Schumann 1781)

Structures such as (2) above are best seen to involve a possessive/modification relation, instantiated by the juxtaposition of the Ground (hosso 'house') and the following locative element (inni 'inside'), the latter of which functions as the possessed/head noun. This kind of spatial relation may also be realised through the inverse constituent order without a change in meaning (cf. Essegbey 2005: 237); the locative noun precedes the Ground NP in a prepositional phrase introduced by the general locative preposition $n a$ 'LOC', as in (3). Such pre-Ground structures have also been recorded in the language since earliest times (see Essegbey and Bruyn 2002, Van den Berg 2007). Note the optionality of the locative preposition $n a$ in (3):

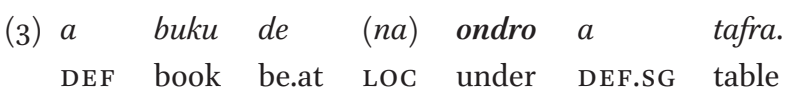

'The book is under the table.' (Sranantongo)

The grammaticality of both pre- and post-positional structures notwithstanding, post-positional structures are totally absent in our field data. We must conclude that the development towards prepositional structures has been completed, at least in the varieties that we have studied, and across all types of text genres in our corpus. This means that locative constructions involving postpositions are no longer in use by the vast majority of speakers. This is confirmed by grammaticality judgments submitted to a sub-section of our language informants. Five speakers below twenty-five years of age perceived postpositional structures to be wrong, and highly unusual at best. Three speakers of around fifty years of age were familiar with postpositional structures but said they would not use them. One speaker of ninety years expressed a preference 
for post-positional structures but conceded that these would be considered unusual by younger speakers.

We assume that language contact with Dutch is primarily responsible for the consolidation of prepositional locative constructions in Sranantongo. For one, all informants from whom the present data was collected consider themselves to be fluent speakers of (Surinamese) Dutch. Secondly, the data was collected in Paramaribo and adjoining areas, hence within the (peri-) urban zone that we have identified as the focal area of language contact in Suriname, and the area within which Dutch is most widely spoken alongside other languages. With respect to the linguistic factors that speak for convergence towards Dutch, prepositional structures are the only option in Dutch, at least in the expression of core spatial relations like 'under', 'in' or 'on'. Perhaps a contributing cause is also a typological pressure to align constituent order in locative constructions with Sranantongo's svo word order. Compare the following Dutch constructions.

(4) de jonge-man gaat de ballen in een doos zetten. the young-man goes the balls in a box put 'The youngster goes to put the ball into a box.' (Surinamese Dutch)

(5) een muis slaapt onder de boom.

a mouse sleeps under the tree

'A mouse is sleeping under the tree.' (Surinamese Dutch)

On a side note, example (4) features a typically Surinamese characteristic, namely the use of zetten as a general placement verb-Speakers of Netherlands Dutch would rather use verbs like plaatsen 'to place', stoppen 'put (inside)' or doen 'put', lit. 'do'. Example (5) does not, however, feature any specifically Surinamese structures or lexical usages.

A closer look at prepositional structures provides another indication of the contact-induced changes in the expression of spatial relations in Sranantongo. We have seen that the general locative preposition $n a$ 'LOC' is optional in prepositional structures, cf. (3). The co-occurrence of $n a$ with a following locative element (the Region or Search Domain element) varies greatly, however. In our corpus, the omission of $n a$ with the locative element ini 'in(side)', as exemplified in (6) is about four times more frequent than with tapu 'upper(side)'.

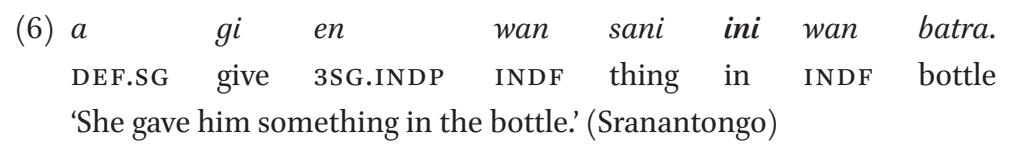


For us, the absence of $n a$ in sentences like (6) is an indication that in $i$ is further along the road of a categorial reanalysis than tapu (and other locative elements like ondro 'under(side)' and baka 'back, behind'). In other words, ini is losing its nominal characteristics and becoming a preposition modeled along its Dutch cognate in. There is no doubt that this contact-induced reanalysis is facilitated by the phonological similarity of the Dutch and Sranantongo forms.

Sranantongo has had both prepositional and postpositional structures from the earliest period of its documented history. The change towards uniquely prepositional structures in contemporary Sranantongo is therefore one of degree rather than outright innovation. Supporting evidence that postpositional structures might, however, have been at least as common as prepositional ones, and possibly even more common in Early Sranantongo comes from Ndyuka, a language that split off from Early Sranantongo in the eighteenth century. In our recordings of contemporary Ndyuka, spatial elements (except the general locative preposition $a$ 'LOC') are only found in the postpositional slot, as is the case with tapu '(on) top (of)' in (7). The nominal character of these "adpositions" transpires in (8), where tapu is used as a common noun in object position:

(7) wan man anga wan uman sidon a wan tafaa tapu. one man and one woman sit Loc one table top 'A woman and a man are sitting at a table.' (Ndyuka)

(8) a wani booko a dalati di lontu tapu. 3SG want break DEF.SG wire suB surround top 'S/he wants to break the wire that goes around the top.' (Ndyuka)

There is one exception, however. The only Ndyuka spatial elements that appears both in the pre- and the postpositional slot is ini 'in(side)' as shown in (9) and (10) respectively:

(9) ne a todo komoto ini a gaasi bataa. then 3SG frog go.out inside DEF.SG glas bottle 'Then the frog came out of the glass bottle.' (Ndyuka)

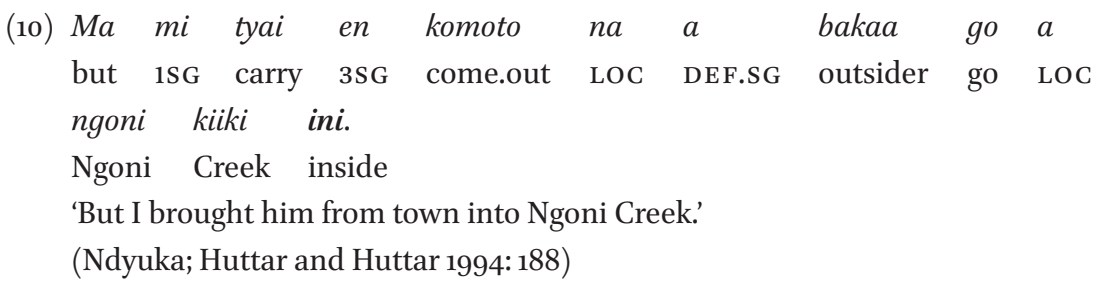


Example (9) suggests that ini is more preposition-like than the other spatial elements in Ndyuka (except, of course the locative preposition $(n) a$ ) for two reasons. Firstly ini may be employed without being preceded by the general locative preposition $n a$, and secondly it may occur before the Ground rather than only after it. In other respects, ini nevertheless behaves more like a nominal element than a preposition. For example, ini can occur independently, just like tapu in (8) above without a following noun specifying Ground, cf (11) below. This is the reason why we gloss ini as 'inside' rather than 'in' (see also Bruyn 1995: 241-253).

(11) da a man teke den san poti a ini.
then DEF.SG man take DEF.PL thing put LOC inside
'Then the man took the things and put them inside.' (Ndyuka)

We can conclude the following from the behaviour of spatial elements in Sranantongo and Ndyuka:

(1) At an earlier stage of its history, Sranantongo featured postpositional structures as the default option, with prepositional structures constituting an alternative option. Through sustained contact with Dutch, the use of pre- vs. postpositional structures shifted in favour of the former in Sranantongo; the shift has been completed in contemporary Sranantongo, which has all but discarded postpositional structures;

(2) Ini 'in' is the most preposition-like of all spatial elements in contemporary Sranantongo (except $n a$ 'loc') and in contemporary Ndyuka. In Sranantongo, the categorial shift of ini towards preposition has, however, progressed further than in Ndyuka.

One possible explanation for $(\mathrm{b})$ is that the ongoing reanalysis of ini as a preposition in contemporary Sranantongo was facilitated because ini might already have had more prepositional characteristics than other locative elements in Early Sranantongo (see Bruyn 1995; Van den Berg 2007). While locative elements such as tappo 'top, on top of, upside' and bakka 'back, at the back of, behind' among others are found as prepositions as well as postpositions in various eighteenth century sources of Early Sranan, ini occurs more frequently before the Ground than after it in the same sources. Further evidence for this is the observation that ini is also more preposition-like in Ndyuka, which split of from Sranantongo in the early eighteenth century. Sranantongo has, however, had longer and more intense contact with Dutch, and this is probably why ini is even more preposition-like in Sranantongo than in Ndyuka. An alternative explanation for (b) is that Ndyuka ini acquired its preposition-like 
characteristics through contact with Sranantongo and Dutch in more recent times rather than through inheritance from the period of its split off.

\subsection{Basic Word Order in Sarnami}

We now turn to changes in basic word order in Sarnami. Our analyses suggest that basic word order in Sarnami is converging with word order in Sranantongo and Surinamese Dutch. As observed for Sranantongo in the preceding section, our informants were multilingual without exception, considering themselves to be fluent in Dutch, and to a slightly lower degree in Sranantongo, alongside Sarnami. Besides speakers from Paramaribo and its surroundings, our pool of Sarnami speakers also includes a substantial number of informants (about a third of the total) from the Nickerie district, the second largest agglomeration of the country. The fact that most Sarnami speakers from Nickerie, a largely mono-ethnic Indo-Surinamese district, also profess to be competent in Sranantongo shows how far Sranantongo has gone to become an ethnically neutral national lingua franca, albeit without the institutional support enjoyed by Dutch.

Like other Indic languages, Sarnami main clauses normally have a SubjectObject-Verb (sov) order (Marhé 1985: 26), compare (12):

$\begin{array}{llll}\text { (12) ego } & \text { manai } & \text { ego } & \text { dosulá-il hai } \\ \text { INDF } & \text { person INDF } & \text { box bring-PSTP } & \text { be.PRS } \\ \text { 'A person has brought a box.' (Sarnami) } & \end{array}$

Word order is nevertheless quite flexible in the Indic languages, and may vary in accordance with syntactic and pragmatic factors. In most Indic languages, speakers may also use a Subject-Verb-Object (svo) order if they want to emphasise the Object, as in the following Hindi sentence:
(13) Mohan ne de dĩ
apnī
kitabẽ fyam ko.
NAME ERG give give.PERF.F.PL REFL.POSS.F book.F.PL NAME DAT
'Mohan has given his book to Sham.' (Hindi; Kachru 2006: 160)

We also find svo basic word order in Sarnami, as shown in (14). A closer look at the Sarnami texts in our corpus, however, show that svo is common in contexts where an emphasis of the Object is unlikely. Yakpo and Muysken (2014) compare a corpus of narrative texts in Sarnami and its closely related Indian sister languages Bhojpuri and Maithili, and find a statistically significant difference between the Suriname and India data in the frequency of svo in main 
clauses: The average frequency of $36 \%$ of svo basic word order across a sample of Sarnami texts is nine times higher than that of a corresponding sample of Indian sister languages.

(14) tab u dekh-il ego hol jamin meñ. then DIsT see-PSTP one hole ground in

'Then he saw a hole in the ground.' (Sarnami)

The high frequency of svo in the Sarnami corpus appears to be the result of convergence with Sranantongo and Surinamese Dutch. In Sranantongo, svo is the only acceptable basic word order in main clauses. Compare the following sentence:

(15) dan a boi si wan olo.

then DEF.SG boy see INDF hole

'Then the boy saw a hole.' (Sranantongo )

Dutch is generally considered a mixed word order language in which the occurrence of sov and svo is conditioned by syntactic factors. We could therefore assume, a priori, that word order in in Surinamese Dutch does not necessarily exert as strong a pressure towards svo in Sarnami as Sranantongo. A number of factors, however, point towards Dutch as a donor language of svo alongside Sranantongo. For one part, Surinamese Dutch, like Netherlands Dutch, features svo basic word order when the predicate is 'simple', i.e. consists of a single word, cf. (16).

(16) het jongetje ziet een gat in een boom.

the boy sees a hole in a tree

'The boy sees a hole in the a tree.' (Surinamese Dutch)

Secondly, word order is SAuxOV in Dutch main clauses featuring complex predicates consisting of an auxiliary verb and a participial main verb, as in (17). Here the main verb (gezien 'seen') is clause-final, but the object (een gat 'a hole') follows the inflected verb (the auxiliary heeft 'has'):

(17) het jongetje heeft een gat in een boom gezien. the boy has a hole in a tree seen

'The boy has seen a hole in a tree.' (Surinamese Dutch) 
In contrast to Dutch, Sarnami is much stricter in its Sov order. A Sarnami sentence analogous to (17) normally features a clause-final Aux (hence SOVAux), as can be seen in (12) (with ego dosu 'a box' and hai 'is' as $\mathrm{O}$ and Aux respectively), the object therefore precedes the inflected verb.

A third characteristic pointing towards convergent pressure towards svo in Sarnami from both Sranantongo and Dutch is the situation in Dutch with respect to subordinate clauses. While Netherlands Dutch has sov order in most types of subordinate clauses, Surinamese Dutch has been shown by de Kleine (2002) to show considerable variability between sov (cf. (18) and svo (cf. (19) in such clauses. The presence of svo in Surinamese Dutch subordinate clauses is in itself a structural feature borrowed from Sranantongo (ibid.):

$\begin{array}{lllllllll}\text { (18) } \begin{array}{l}\text { want } \\ \text { because }\end{array} \text { she knows that I not of those things like } & \end{array}$ 'Because she knows I don't like such things.' (Netherlands Dutch; de Kleine 2002: 125)

(19) want ze weet ik hou niet van die dingen. because she knows I like not of those things 'Because she knows I don't like such things.' (Surinamese Dutch; de Kleine 2002: 125)

An exploratory analysis of our data also points to word order correlations with svo basic word in Sarnami, even if these observations require further in-depth investigation. Our Sarnami corpus seems to feature a higher number of relative clauses that follow rather than precede their head nouns, as in the following example:

$\begin{array}{rlllllllll}\text { (20) } u & \text { ego } & \text { dosu } & \text { lá-il } & \text { hai } & \text { [jaun } & \text { pe thará } & \text { hoi } & \text { sake }\end{array}$ 'He has brought a box that he can stand on.' (Sarnami)

In Sarnami's next relatives in India, both preposed and postposed relative clauses orders appear to be roughly equally common. Example (21) from Maithili, one of the contributing languages of Sarnami, shows a preposed relative clause. This order comes along with the correlative structure so typical of Indic; the postposed main clause contains the correlative marker se. Such correlative structures as in (21) are infrequent in the Sarnami data investigated so far, and surpassed in frequency by postposed structures of the type provided in (20) above: 

(21) $[$ je kailh rait nac-al] se $u$ natua ekhan utal REL yesterday night dance-PST COREL DIST dancer now asleep aich.
be.PRS
'The dancer who danced last night is now asleep.' (Maithili; Yadav 1996: 356)

Relative constructions involving a single relative pronoun and a post-posed relative clause also represent the most neutral type of structure in Sranantongo and Dutch, compare (22) and (23) respectively. We therefore assume the preference for such structures in Sarnami to once more be a consequence of convergent pressure from Sranantongo and Dutch:

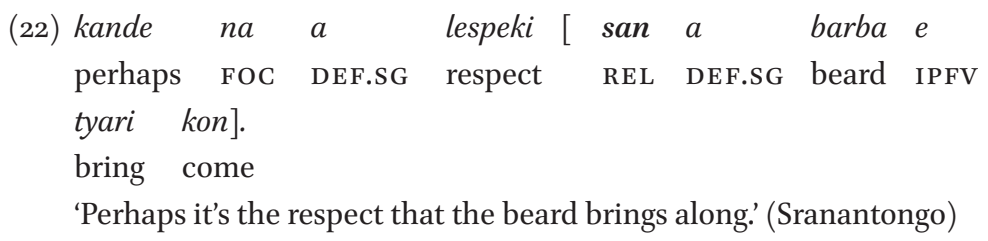

(23) een vrouw gooit een bijl op de bord [die dan

a woman throws an axe on the plate REL then vervolgens in stukken breekt]. afterwards in pieces breaks

'A woman throws an axe on the plate, which then breaks into pieces.' (Surinamese Dutch)

To sum up, Sarnami and its Indian relatives both manifest sov and svo in main clauses. In the Indian languages, svo is a pragmatically marked word order employed to signal focus of the object. However, Sarnami shows a much higher frequency of svo than the Indian languages. We have interpreted this as an indication that svo is no (more) a pragmatically marked word order in Sarnami, and is instead competing with sov as an unmarked word order. We see this change in progress in Sarnami to be induced by contact with Sranantongo and Dutch. A similar picture emerges in relative constructions, where postposed relative clauses modelled on Sranantongo and Dutch seem to be more common than other, typically Indic structures. We are therefore witnessing multidirectional convergence, in which both Surinamese Dutch and Sranantongo are contributing to contact-induced change in Sarnami. At the same time Dutch seems to have borrowed structures from Sranantongo as well, as shown with respect to word order in subordinate clauses. 


\subsection{Expression of Tense, Mood and Aspect in Ndyuka}

While there is considerable overlap in TMA forms among the Surinamese creole languages, the semantic realms covered by these forms do not always coincide. The meanings of modal auxiliaries, in particular, are quite variable among the creoles. Here the focus will be on the area of epistemic probability, as well as deontic possibility and permission. These are the modal categories that correspond among the Surinamese creoles despite being conveyed by different forms (Migge 2006: 34; Migge and Goury 2008: 309; Migge and Winford 2009). Due to an increasing number of Maroons in the city, their knowledge of Sranantongo, frequent interaction with Maroons from other ethnic groups as well as non-Maroons and perhaps the inclination to establish an identity independent of their traditional ethnicity (see Migge 2007; Migge and Léglise 2013; Léglise and Migge, this volume), Maroon languages have come under influence of each other and Sranantongo. Ndyuka speakers themselves are also aware of Sranantongo's influence on their language. One informant explained that the closer you get to the coast, the more 'developed' the language is. Others describe the influence more defensively; coastal Ndyuka is moksi 'mixed' or basaa 'mixed'. An urban dwelling informant describes the difference in terms of "modern" Ndyuka along the coast versus a more traditional variety in the interior. Language attitudes aside, speakers are well aware that there is a difference between urban and rural varieties, though it is often difficult for informants to pinpoint particular features, while several informants claimed to switch between varieties depending on their environment. Table 8.6, where the Sranantongo and Rural Ndyuka columns are adapted from Migge (2006: 34), and Migge and Goury (2008: 399), illustrates how the modal categories of Urban Ndyuka (our data) have been influenced by Sranantongo:

TABLE 8.6 Modal particles in rural and urban Ndyuka

\begin{tabular}{llll}
\hline Modal category & Sranantongo & Rural Ndyuka & Urban Ndyuka \\
\hline Positive potential & sa & sa & sa \\
Negative potential & $\mathrm{kan} / \mathrm{sa}$ & poi & poi \\
Positive possibility & $\mathrm{kan}$ & sa & kan \\
Negative possibility & $\mathrm{man} / \mathrm{kan}$ & poi & poi \\
Positive permission & $\mathrm{man} / \mathrm{kan} / \mathrm{mag}$ & sa & kan \\
Negative permission & $\mathrm{man} / \mathrm{kan} / \mathrm{mag}$ & poi & man \\
Positive physical ability & $\mathrm{man} / \mathrm{kan}$ & sa & kan \\
Negative physical ability & $\mathrm{man} / \mathrm{kan}$ & poi & poi
\end{tabular}


Examples from naturalistic and elicited speech of city-dwelling (Paramaribo) Maroons recorded in 2011 demonstrate that the modal categories of Sranantongo have encroached upon those of urban Ndyuka. The following two examples contrast the rural Ndyuka form poi (<Portuguese pode ' 3 SG can') in (24) with the form man (<Dutch/English man 'man') in (25). Both forms may express negative permission (the former only in combination with verbal negation), in this context, they thus share the same function. Although man is also attested in upriver Ndyuka and Pamaka (Bettina Migge, p.c.), it has probably only been further entrenched in the speech of urban Ndyuka informants and appears to be preferred over poi. Compare the corresponding Sranantongo example in (26):

(24) mi be taigi den
1sg PST tell DEF.PL child COMPL 2SG NEG MOD walk
go a $\quad$ busi
go LOC forest

(25) $i$ no man oli en moro.

2s NEG MOD hold 3SG.INDP more

'You may not keep it anymore.' (Urban Ndyuka)

(26) un no man taki soso Sranantongo.

1/2PL NEG MOD talk only Sranantongo

'You [PL] may not talk only Sranantongo.' (Sranantongo)

The following examples illustrate the phenomenon with respect to the expression of physical ability. The conventional form for expressing this modal category in rural Ndyuka is the preverbal particle $s a$, as shown in (27). Urban Ndyuka speakers, however, freely employ the Sranantongo derived auxiliary verb kan instead, as in (28). Compare the Sranantongo use of kan in (29):

(27) a taanga, a sa diki wan ondoo kilo. 3SG be.strong 3SG MOD lift one hundred kilo 'He is (very) strong, he can lift 100 kilos.' (Rural Ndyuka; Winford and Migge 2004: 30)

(28) $i$ kan go meke wan film.

2SG MOD go make INDF film

'You can go make a film.' (Urban Ndyuka) 


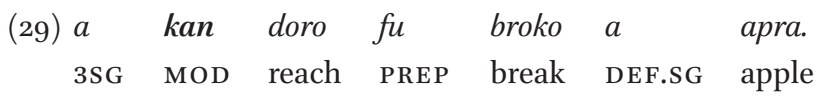
'He can manage to pick the apple.' (Sranantongo)

It is important to note here that the phenomenon presented cannot be described as a change that is complete; variation is the norm. Many of our urban informants were recorded using both rural Ndyuka forms next to urban forms, though this was not necessarily the case with upriver speakers. With two geographic points of reference in our Ndyuka sample, Paramaribo and the upriver Tapanahoni, the data suggest that Sranantongo is the main source of urban features in Ndyuka, but contact with highly intelligible eastern Maroon varieties should not be ignored. In fact, it is often difficult to determine the origin of a particular feature, such as the case of man in examples (24)-(26). Pamaka in not represented in our sample, though Migge and Goury (2008: 309) tell us that man is also employed for several modal categories in that language. Kan on the other hand appears to be an addition to the repertoire of urban Ndyuka originating from Sranantongo. Admittedly, etymologically iffy features such as man might weaken our argument for an urban influence on Ndyuka. However, it should be noted that the breakdown of traditional Maroon social systems in Paramaribo and urban centers along the Marowijne have set the stage for the blurring of some of the socially salient differences among Maroon varieties and opened the gates for influence from Sranantongo. It remains to be seen whether we are witnessing a diachronic change in progress. It is nonetheless certain that the causes of the variation we have registered can only partially be explained in terms of geography or urbanisation. Contextual factors, such as speaker and interlocutor identities, social setting, and language attitudes, also play a significant role in determining the distribution of linguistic variables, such as the modal forms described here (cf. Léglise and Migge, this volume).

\section{Conclusion}

The complex multilingual setting of Suriname cannot be regarded as a case of stable bilingualism or diglossia. We have presented examples of contactinduced changes in three languages of Suriname, namely Sranantongo, Ndyuka and Sarnami, in three language contact constellations that are typical for Suriname where Dutch and Sranantongo act as sources of change and targets of convergence and language shift: 
(1) Locative constructions in Sranantongo are now more similar to Dutch than they were before. This case exemplifies contact with Dutch as the agent and another language (in this case Sranantongo) as the undergoer of a linguistic change (section 5.1).

(2) Word order changes in both main clauses and relative clauses are currently in progress in Sarnami, the undergoer of linguistic change in section 5.2. They exemplify multidirectional convergence, as both Surinamese Dutch and Sranantongo function as sources in this case. Note that Surinamese Dutch is not only the source but also the recipient when it comes to word order changes, as it seems to have borrowed structures from Sranantongo, as shown with respect to word order in subordinate clauses.

(3) The observed increase of similarities in the urban Ndyuka modal system with the Sranantongo modal system at the expense of the differences between the Ndyuka and Sranantongo systems illustrate the role of Sranantongo as the agent and another language (in this case Ndyuka) as the undergoer of change (section 5.3).

Some of the examples presented in this paper may well be regarded as pragmatic outcomes of ad-hoc strategies of individual speakers in response to the communicative challenges of the multilingual discourse setting, as well as identity performance, etc. Other examples, however, suggest that these pragmatic outcomes have become regularised and that language change has occurred (Sranantongo ini), may be occurring (Sarnami word order change) or that a new code has emerged, as in the case of Ndyuka. Our study suggests that social constraints and communicative norms that control language use in Suriname are changing. These changes may be influenced by increased speaker mobility along a geographical dimension (improved infrastructure; the emergence of the peri-urban region, and transmigration), as well as a social dimension (schooling; new (social media) and technologies), resulting in more multilingual encounters. Like all socio-cultural phenomena, language is expected to change. Future investigation will reveal how social and linguistic constraints on convergence and relaxation of norms conspire in the case of the changes that we have observed and how they contribute to the emergence of new practices. 